\section{Cureus}

\title{
The Impact of Hope and Resilience on Multiple Factors in Neurosurgical Patients
}

\author{
Devika Duggal $^{1}$, Amanda Sacks-Zimmerman ${ }^{1}$, Taylor Liberta $^{1}$ \\ 1. Neurological Surgery, Weill Cornell Medical College
}

$\square$ Corresponding author: Taylor Liberta, taylorliberta@mail.adelphi.edu Disclosures can be found in Additional Information at the end of the article

\section{Abstract}

The purpose of the present article is to outline and review the impact of stable psychological characteristics on the emotional and functional outcomes of neurosurgical patients. Neurosurgical patients face adversity as inherent to their diagnoses and, consequently, experience emotional distress. Despite commonalities in diagnoses, diverse outcomes are seen post-neurosurgery, which are influenced by psychological factors. Therefore, an understanding of neurosurgical patients' behavior, thoughts, and feelings surrounding their diagnoses, informed by psychological concepts, is important for both neuropsychology and neurosurgery.

Categories: Neurology, Psychology, Neurosurgery

Keywords: hope, resilience, mood and functioning, treatment outcomes, protective factors, stable psychological traits, neurosurgical outcomes, psychological distress, optimal functioning

\section{Introduction And Background}

\section{Hope and resilience}

Neurosurgery patients face multiple adversities within their illness, including both the physical impact of the disease (i.e., pain and discomfort) and treatment, as well as the psychological aspects of the knowledge of having a potentially life-threatening illness. Hope and resilience are both stable, psychological traits that can act as protective factors against adversity. Hope is an optimistic attitude of mind based on an expectation of positive outcomes. Hope is probably best conceptualized by Snyder [1] as "a positive motivational state that is based on an interactively derived sense of successful (a) agency (goal-directed energy) and (b) pathways (planning to meet goals)" [2]. While the agency component makes available the willpower and determination to achieve goals, the pathways component is responsible for creating alternative routes to pursue these goals. Hopeful individuals possess positive thinking that is reflective of a realistic sense of optimism [3] as well as the belief that they can produce routes to desired goals [4]. Such individuals perceive obstacles as challenges to overcome and are able to utilize their optimism to plan alternatives to achieve their end goal [5]. Studies have found that hope is positively correlated with life satisfaction and serves as a buffer against the impact of negative and stressful life events [6]. Thus, individuals high in hope tend to show better athletic, academic, occupational, and health outcomes [5]. Hope can exist even in the context of a life-threatening health condition and can perhaps lead to better outcomes, as will be the premise for the present article.

Resilience is an individual's ability to adaptively respond to hardship, stress, and adversity [7] and has been defined as the ability to "bounce back" from negative events without succumbing to despair [8]. Individuals who report high levels of resilience typically portray an optimistic outlook, positive emotionality, curiosity, and openness to new experiences [8]. These positive 
emotions, in turn, typically lead to constructive attitudes and behaviors [9]. High resilience helps individuals positively cope with uncertainty, conflict, and failure [9]. The ability to positively cope with adverse events allows resilient individuals to adapt to significant life changes and, consequently, function better as they are able to emerge from a challenge stronger, wiser, and more powerful. Researchers have found that resilience correlates strongly with health and longevity, success, interpersonal satisfaction, and happiness [10]. Hope and resilience are closely aligned constructs, as they both include a tendency towards maintaining an optimistic outlook in the face of adversity.

\section{Review}

\section{Impact of hope and resilience on mood and functioning}

Possessing hope and resilience positively affect mood and functioning. Hope and resilience have been associated with better physical and mental health outcomes in undergraduates [11] as well as better health and well-being and lower psychological distress in adults [12-13]. In addition, Ryden, et al. found that resilience is a protective factor against depression and the impact of stress [14]. Additionally, both traits have been found to positively influence the quality of life as well as act as a buffer against the negative impact of stressors [15]. Studies have found that an inverse relationship exists between optimism and depressive symptoms [16] as well as between optimism and suicidal ideation [17]. These findings have been consistently observed across a number of studies. Specifically, Gooding, et al. [18] indicated that higher levels of hope countered the negative effects of depression on resilience related to emotional regulation. Additionally, patients who report higher levels of hope and resilience are less likely to show mood disturbances [19] and tend to possess higher self-esteem [20]. By contrast, low levels of hope have been associated with depression [21].

\section{Hope and resilience in the context of a medical illness}

The optimistic attitude inherent in hopeful individuals plays a key role in successfully coping with a medical illness and its prognosis, as well as in improving health-related quality of life [22]. This is likely due to the strong relationship between hope, resilience, and mood. Many studies have shown that mood states have a direct impact on physical health. For instance, indices of positive mood are associated with biological health markers, such as immune system response, cortisol profiles, and cardiovascular function [23]. In contrast, negative emotional states tend to correlate with excessive somatic symptoms [24]. Giltay, et al. [25] noted that optimism predicted less probability of mortality in general and, in particular, of cardiovascular mortality in a population of older adults. A study conducted on an oncological population found that low levels of hope significantly predicted premature mortality in young patients with breast cancer [26]. Hopeful and optimistic patients with head and neck cancer showed greater survival rates a year after diagnosis when compared to pessimists [27]. Ironson, et al. [28] suggested that optimism, less avoidant coping strategies, and lower levels of depression positively influence the prognosis of patients diagnosed with AIDS. A review study found that resilience is associated with positive factors specifically linked to physical illness, such as selfcare, adherence to treatment recommendations, illness perception, and physical exercise [29]. Resilience was also found to be associated with a higher quality of life and lower emotional distress as well as fatigue in cancer patients and survivors [30]. The aforementioned studies suggest that the relationship between hope, resilience, and mood may influence physical health by encouraging involvement in health-promoting behaviors [31].

\section{Psychological distress and treatment outcomes}

Emotional distress is a commonly observed symptom in individuals who receive diagnoses that require neurosurgical intervention and is predictive of poor health-related behaviors, including smoking, alcohol use, fatigue, and sleep difficulties [32]. Individuals given a neurological 
diagnosis requiring surgical intervention are understandably more susceptible to psychological disturbances, such as anxiety and depression. The overwhelming level of stress accompanying neurological diagnoses contributes to individual feelings of helplessness and hopelessness, often leading to negative mood states. Diagnoses with a variable to negative prognoses are prevalent in the neurosurgical field, including epilepsy, cerebral aneurysms, tumors, moderate to severe brain injuries, and spinal cord degeneration. Additionally, neurosurgical intervention, despite being beneficial, can negatively impact mood and/or daily functioning. After the neurosurgical intervention, individuals often experience cognitive dysfunction and mood changes in varying degrees (including irritability, low mood, anxiety, diminished attention, and processing speed) [33]. The presence of these mood states and emotions, in turn, may lead to poor treatment outcomes, including a higher rate of mortality [34]. Psychological distress and depressive symptoms are observed in the face of diseases and are typically associated with poor self-care and management. For instance, a longitudinal study linked distress to poor medication adherence and self-management (through diet and exercise) in Type 2 diabetic patients [35]. Studies on brain tumor patients have shown that psychological distress contributes to the deterioration of the quality of life and is implicated in the morbidity and mortality of brain tumor patients [36-37]. While it remains unclear exactly how mood disturbances and poor outcomes are linked, it is possible that negative mood states negatively affect the motivation to engage in health-related behaviors to enhance recovery.

\section{Hope and resilience as protective factors}

Protective factors are circumstances or attributes that help individuals deal more effectively with stressful events. Hope and resilience can act as protective factors against the subjective experience of hardship, specifically of receiving a potentially adverse medical diagnosis. These traits may help individuals overcome and/or become proactive in the context of medical diseases by making individuals less susceptible to negative mood states, which negatively impact physical health. Several studies have examined the relationship between hope, resilience, and coping techniques in the context of medical illness.

Resilience recognizes the need to take both reactive and proactive measures when faced with hardship. Resilience ameliorates the destructive impact of negative or traumatic events and, through psychological elasticity, contributes to recuperation from these hardships. Resilience also proactively uses setbacks as opportunities for growth [38]. While hope promotes a generally positive outlook, resilience facilitates the thought processes that underlie flexibility, adaptation, and, at times, improvisation in situations that are typically marked by uncertainty. Both hope and resilience facilitate the search for meaning despite circumstances that do not lend themselves to rational and logical explanations [39].

Hopeful and resilient individuals are often characterized by positive attitudes and optimistic outlooks. Positivity and optimism, in turn, are associated with better mood states as well as decreased occurrences of stress-related illnesses and reduced use of medical services [40]. These adaptive traits help to replenish emotional resources, relieve potential suffering, and enhance positive coping methods [41]. Studies of individuals with cancer have suggested that resilience provides at least partial protection against emotional distress, leading to better emotional adjustment [42]. Other studies have indicated that aspects of hope and resilience, such as positive expectations and optimism, have predicted better health outcomes after heart transplantation and coronary bypass surgery [43-44]. Another study has shown that promoting positivity can help prevent relapse of depression during the residual phase, where the risk of relapse is particularly high [45].

\section{Promoting optimal functioning}

Given the present literature, it is clear that there is a need to go beyond traditional efforts of 
resisting and/or recovering from a disease. A greater focus on psychological treatment, specifically the promotion and understanding of the conditions that promote hope and resilience, is critical. A review study found that the factors associated with and/or predictive of resilience are self-efficacy, self-esteem, internal locus of control, optimism, mastery, social support, hardiness, empowerment, acceptance, determinism, personal growth, social support, coping strategies, spirituality, cognitive appraisal, and a sense of coherence [32].

Rousseau [22] found that hope is augmented by strengthening interpersonal relationships, exploring one's faith, and learning to control one's symptoms. Another study found that individuals with high levels of hope reported significantly higher levels of personal adjustment and global life satisfaction [46]. Furthermore, these individuals reported significantly less emotional distress [46]. These findings suggest that efforts to increase individuals' levels of hope and resilience may promote optimal functioning in multiple life domains and can be developed through psychological treatment.

\section{Current investigation and future research directions}

Neurosurgery patients face multiple adversities within their illness involving both the physical impact of the disease and treatment, as well as the psychological aspects of the knowledge of having a potentially life-threatening illness. Studies examining the impact of hope and resilience on mood and functional outcomes in neurosurgical populations are scarce. Bunevicius, et al. [47] suggest that psychological distress, which leaves one vulnerable to anxiety and depression, is prevalent in brain tumor patients. These factors contribute to deterioration in health-related quality of life and are associated with increased mortality of brain tumor patients $[35,48]$. It is possible that characteristics of hope and resilience may help individuals cope with psychological distress effectively and, consequently, engage in more appropriate health-related behaviors.

To this end, the present authors, psychologists within the Weill Cornell Department of Neurosurgery, are investigating the impact of hope and resilience on emotional states, functionality, and disease prognosis in pre- and post-neurosurgical individuals. The authors are expecting to enroll approximately 70 participants who have recently received a neurosurgical diagnosis. These individuals will be given a battery of tests that measure their hope and resilience levels as well as their present emotional and functional states. The Adult Hope Scale (AHS) and Resilience Scale (RS) will be used to assess hope and resilience; the Beck Depression Inventory (BDI) and Beck Anxiety Inventory (BAI) will measure characteristic attitudes and symptoms of depression and anxiety; the Adaptive Behavior Assessment System, Second Edition (ABAS-II) will assess functionality in the domains of communication, community use, functional academics, home living, health and safety, leisure, self-care, selfdirection, social, and work; finally, the Modified Rankin Scale (mRS) will measure the degree of dependency in the daily activities of individuals who have experienced a neurological disability. Approximately six months after participants receive neurosurgical treatment, they will be given the same battery, and changes in mood and functioning will be measured. The authors expect to find that individuals who possess characteristics of hope and resilience prior to neurosurgical intervention will be less vulnerable to negative mood states and more likely to engage in health-promoting behaviors that aid recovery.

\section{Conclusions}

There is a spectrum of human characteristics that affects the relationship between receiving a medical diagnosis and its impact on emotional state. More recently, there has been a growing interest in identifying protective factors that help such patients maintain emotional stability in the face of adverse events [49]. Therefore, measuring hope and resilience may help predict outcomes among people coping with significant medical conditions, which could have 
implications for providing extra support for those patients who are low in these characteristics. Increased knowledge and understanding of these innate characteristics and their relationship with emotional stability and coping can be integrated into supportive services or interventions (e.g., psychological counseling). From this, patients may experience increased quality of life.

\section{Additional Information \\ Disclosures}

Conflicts of interest: In compliance with the ICMJE uniform disclosure form, all authors declare the following: Payment/services info: All authors have declared that no financial support was received from any organization for the submitted work. Financial relationships: All authors have declared that they have no financial relationships at present or within the previous three years with any organizations that might have an interest in the submitted work. Other relationships: All authors have declared that there are no other relationships or activities that could appear to have influenced the submitted work.

\section{References}

1. Snyder CR: Hypothesis: There is Hope. Handbook of Hope Theory, Measures and Applications. Snyder CR (ed): Academic Press, San Diego, CA; 2000. 3-21.

2. Snyder CR, Irving LM, Anderson JR: Hope and Health. Handbook of Social and Clinical Psychology: The Health Perspective. Snyder CR, Forsyth DR (ed): Pergamon Press, New York; 1991. 15:285-305.

3. Goleman D: Emotional Intelligence: Why It Can Matter More Than IQ. Goleman D (ed): Bloomsbury Publishing PLC, New York, NY; 1996.

4. Ciarrochi J, Heaven PCL, Davies F: The impact of hope, self-esteem, and attributional style on adolescents' school grades and emotional well-being: A longitudinal study. J Res Pers. 2007, 41:1161-78. 10.1016/j.jrp.2007.02.001

5. Luthans F, Avey JB, Avolio BJ, Peterson SJ: The development and resulting performance impact of positive psychological capital. Human Resource Development Quarterly. 2010, 21:41-67. 10.1002/hrdq.20034

6. Valle MF, Huebner ES, Suldo SM: An analysis of hope as a psychological strength. J Sch Psychol. 2006, 44:393-406.

7. Avey JB, Luthans F, Smith RM, Palmer NF: Impact of positive psychological capital on employee well-being over time. J Occup Health Psychol. 2010, 15:17-28. 10.1037/a0016998

8. Tugade MM, Fredrickson BL: Resilient individuals use positive emotions to bounce back from negative emotional experiences. J Pers Soc Psychol. 2004, 86:320-33. 10.1037/00223514.86.2.320

9. Avey JB, Wernsing TS, Luthans F: Can positive employees help positive organizational change? Impact of psychological capital and emotions on relevant attitudes and behaviors. J Appl Behav Sci. 2008, 44:48-70. 10.1177/0021886307311470

10. Schneider S: In search of realistic optimism. Meaning, knowledge, and warm fuzziness . Am Psychol. 2001, 56:250-63. 10.1037//0003-066X.56.3.250

11. Scheier MF, Carver CS: Optimism, coping, and health: assessment and implications of generalized outcome expectancies. Health Psychol. 1985, 4:219-47. 10.1037/02786133.4.3.219

12. Kylma J: Dynamics of hope in adults living with HIV/AIDS: a substantive theory . J Adv Nurs. 2005, 52:620-30. 10.1111/j.1365-2648.2005.03633.x

13. Greiner KA, Born W, Nollen N, Ahluwalia JS: Knowledge and perceptions of colorectal cancer screening among urban African Americans. J Gen Intern Med. 2005, 20:977-83.

10.1007/s11606-005-0244-8

14. Rydén A, Karlsson J, Sullivan M, Torgerson JS, Taft C: Coping and distress: what happens after intervention? A 2-year follow-up from the Swedish Obese Subjects (SOS) study. Psychosom Med. 2003, 65:435-42. 10.1097/01.PSY.0000041621.25388.1A

15. Wu HC: The protective effects of resilience and hope on quality of life of the families coping with the criminal traumatisation of one of its members. J Clin Nurs. 2011, 20:1906-15. 
10.1111/j.1365-2702.2010.03664.x

16. Hart SL, Vella L, Mohr DC: Relationships among depressive symptoms, benefit-finding, optimism, and positive affect in multiple sclerosis patients after psychotherapy for depression. Health Psychol. 2008, 27:230-38. 10.1037/0278-6133.27.2.230

17. Hirsch JK, Conner KR, Duberstein PR: Optimism and suicide ideation among young adult college students. Arch Suicide Res. 2007, 11:177-85. 10.1080/13811110701249988

18. Gooding PA, Hurst A, Johnson J, Tarrier N: Psychological resilience in young and older adults. Int J Geriatr Psychiatry. 2012, 27:262-70. 10.1002/gps.2712

19. Acquaye AA, Lin L, Vera-Bolanos E, Gilbert MR, Armstrong TS: Hope and mood changes throughout the primary brain tumor illness trajectory. Neuro Oncol. 2016, 18:119-125. 10.1093/neuonc/nov101

20. Curry LA, Snyder CR, Cook DL, Ruby BC, Rehm M: Role of hope in academic and sport achievement. J Pers Soc Psychol. 1997, 73:1257-67. 10.1037//0022-3514.73.6.1257

21. Snyder CR, Lopez SJ, Shorey HS, Rand KL, Feldman DB: Hope theory, measurements, and applications to school psychology. Sch Psychol Q. 2003, 18:122-39.

10.1521/scpq.18.2.122.21854

22. Rousseau P: Hope in the terminally ill. West J Med. 2000, 173:117-18.

23. Dockray S, Steptoe A: Positive affect and psychobiological processes. Neurosci Biobehav Rev. 2010, 35:69-75. 10.1016/j.neubiorev.2010.01.006

24. Martínez-Correa A, Reyes del Paso GA, García-León A, González-Jareño MI: Relationship between dispositional optimism/pessimism and stress coping strategies (Article in Spanish). Psicothema. 2006, 18:66-72.

25. Giltay EJ, Geleijnse JM, Zitman FG, Hoekstra T, Schouten EG: Dispositional optimism and allcause and cardiovascular mortality in a prospective cohort of elderly Dutch men and women. Arch Gen Psychiatry. 2004, 61:1126-35. 10.1001/archpsyc.61.11.1126

26. Schulz R, Bookwala J, Knapp JE, Scheier M, Williamson GM: Pessimism, age, and cancer mortality. Psychol Aging. 1996, 11:304-309. 10.1037/0882-7974.11.2.304

27. Allison PJ, Guichard C, Fung K, Gilain L: Dispositional optimism predicts survival status 1 year after diagnosis in head and neck cancer patients. J Clin Oncol. 2003, 21:543-48.

10.1200/JCO.2003.10.092

28. Ironson G, Balbin E, Stuetzle R, Fletcher MA, O’Cleirigh C, Laurenceau JP, Schneiderman N, Solomon G: Dispositional optimism and the mechanisms by which it predicts slower disease progression in HIV: proactive behavior, avoidant coping, and depression. Int J Behav Med. 2005, 12:86-97. 10.1207/s15327558ijbm1202_6

29. Stewart DE, Yuen T: A systematic review of resilience in the physically ill . Psychosomatics. 2011, 52:199-209. 10.1016/j.psym.2011.01.036

30. Strauss B, Brix C, Fischer S, Leppert K, Füller J, Roehrig B, Schleussner C, Wendt TG: The influence of resilience on fatigue in cancer patients undergoing radiation therapy (RT). J Cancer Res Clin Oncol. 2007, 133:511-18. 10.1007/s00432-007-0195-z

31. Pressman SD, Cohen S: Does positive affect influence health? . Psychol Bull. 2005, 131:925-71. 10.1037/0033-2909.131.6.925

32. Zeltzer LK, Recklitis C, Buchbinder D, Zebrack B, Casillas J, Tsao JC, Lu Q, Krull K: Psychological status in childhood cancer survivors: a report from the Childhood Cancer Survivor Study. J Clin Oncol. 2009, 27:2396-404. 10.1200/JCO.2008.21.1433

33. Liu R, Page M, Solheim K, Fox S, Chang SM: Quality of life in adults with brain tumors: current knowledge and future directions. Neuro Oncol. 2009, 11:330-39. 10.1215/152285172008-093

34. Chida Y, Hamer M, Wardle J, Steptoe A: Do stress-related psychosocial factors contribute to cancer incidence and survival?. Nat Clin Pract Oncol. 2008, 5:466-75. 10.1038/ncponc1134

35. Gonzalez JS, Delahanty LM, Safren SA, Meigs JB, Grant RW: Differentiating symptoms of depression from diabetes-specific distress: relationships with self-care in type 2 diabetes. Diabetologia. 2008, 51:1822-25. 10.1007/s00125-008-1113-x

36. Litofsky NS, Resnick AG: The relationships between depression and brain tumors . J Neurooncol. 2009, 94:153-61. 10.1007/s11060-009-9825-4

37. Mainio A, Hakko H, Timonen M, Niemelä A, Koivukangas J, Räsänen P: Depression in relation to survival among neurosurgical patients with a primary brain tumor: a 5-year follow-up study. Neurosurgery. 2005, 56:1234-41. 10.1227/01.NEU.0000159648.44507.7F

38. Youssef CM, Luthans F: Positive organizational behavior in the workplace: the impact of hope, 
optimism, and resilience. J Management. 2007, 33:774-800. 10.1177/0149206307305562

39. Coutu DL: How resilience works. Harv Bus Rev. 2002, 80:46-56.

40. Haglund ME, Nestadt PS, Cooper NS, Southwick SM, Charney DS: Psychobiological mechanisms of resilience: relevance to prevention and treatment of stress-related psychopathology. Dev Psychopathol. 2007, 19:889-920. 10.1017/S0954579407000430

41. Folkman S, Moskowitz JT: Stress, positive emotion, and coping. Curr Dir Psychol Sci. 2000, 9:115-18. 10.1111/1467-8721.00073

42. Markovitz SE, Schrooten W, Arntz A, Peters ML: Resilience as a predictor for emotional response to the diagnosis and surgery in breast cancer patients. Psychooncology. 2015, 24:1639-45. 10.1002/pon.3834

43. Leedham B, Meyerowitz BE, Muirhead J, Frist WH: Positive expectations predict health after heart transplantation. Health Psychol. 1995, 14:74-79. 10.1037/0278-6133.14.1.74

44. Fitzgerald TE, Tennen H, Affleck G, Pransky GS: The relative importance of dispositional optimism and control appraisals in quality of life after coronary artery bypass surgery. J Behav Med. 1993, 16:25-43. 10.1007/BF00844753

45. Fava GA, Rafanelli C, Grandi S, Conti S, Belluardo P: Prevention of recurrent depression with cognitive behavioral therapy: preliminary findings. Arch Gen Psychiatry. 1998, 55:816-20. 10.1001/archpsyc.55.9.816

46. Gilman R, Dooley J, Florell D: Relative levels of hope and their relationship with academic and psychological indicators among adolescents. J Soc Clin Psychol. 2006, 25:166-78.

10.1521/jscp.2006.25.2.166

47. Bunevicius A, Tamasauskas S, Deltuva V, Tamasauskas A, Bunevicius R: Psychological distress symptoms' clusters in brain tumor patients: factor analysis of depression and anxiety scales. Psychooncology. 2013, 22:2860-63. 10.1002/pon.3354

48. Gathinji M, McGirt MJ, Attenello FJ, Chaichana KL, Than K, Olivi A, Weingart JD, Brem H, Quinones-Hinojosa A: Association of preoperative depression and survival after resection of malignant brain astrocytoma. Surg Neurol. 2009, 71:299-303. 10.1016/j.surneu.2008.07.016

49. Seligman ME, Csikszentmihalyi M: Special issue: positive psychology. Am Psychol. 2000, 55:5-14. 